\title{
La revista Comunidad del obispado de Neuquén
}

\section{Experiencia de denuncia y de comunicación popular}

\author{
The Magazine Community of the Bishopric of Neuquén \\ Experience of Denunciation and Popular Communication
}

\section{Felipe Navarro Nicoletti}

fnavarro.nicoletti@gmail.com

https://orcid.org/0000-0003-3214-3009

\section{María Andrea Nicoletti}

mariaandreanicoletti@gmail.com

https://orcid.org/0000-0001-7661-5413

\section{Consejo Nacional de Investigaciones Científicas y Técnicas (CONICET) \\ Instituto de Investigaciones en Diversidad Cultural y Procesos del Cambio (IIDyPCa) Universidad Nacional de Río Negro | Argentina}

\section{Resumen}

En este artículo, los autores analizan los editoriales de la revista Comunidad, perteneciente al obispado de la ciudad de Neuquén, Argentina, a cargo del obispo Jaime de Nevares; en particular, aquellos discursos referidos a la defensa de los derechos humanos. En el trabajo se realiza un recorrido por la línea editorial de la revista, en el marco del proyecto comunicacional del obispado neuquino, así como por las trayectorias de sus referentes y el contexto sociopolítico de la Dictadura a la que interpelaron. Finalmente, se pone el foco en los editoriales titulados «Habla Jaime», que el Obispo escribía en primera persona prescindiendo de su jerarquía eclesiástica.

Palabras clave

revista, Jaime de Nevares, derechos humanos, Neuquén

\section{Abstract}

In this article, the authors analyze the editorials of the magazine Comunidad, belonging to the bishopric of Neuquén city (Argentina) under the responsibility of Bishop Jaime de Nevares; in particular, those discourses referring to the defense of Human Rights. The work analyzef the editorial line of the magazine, within the communicational project of the Neuquian bishopric, as well as the trajectories of the referents and the sociopolitical context in which they interpellated the dictatorship. Finally, the focus is on titled editorials «James Speaks», that the Bishop wrote in the first person regardless of his ecclesiastical hierarchy.

Keywords

magazine, Jaime de Nevares, human rights, Neuquén 


\section{La revista Comunidad del obispado de Neuquén}

\section{Experiencia de denuncia y de comunicación popular}

\section{Por Felipe Navarro Nicoletti y María Andrea Nicoletti}

En la provincia del Neuquén, Argentina, durante la última Dictadura cívico eclesial militar surgió un proyecto comunicacional popular encabezado por el obispo Jaime de Nevares (1961-1995) que contó con la revista Comunidad, que comenzó a circular en 1980, y con la Radio Comunidad «Enrique Angelelli», que inició sus transmisiones en 1987. Dichos proyectos mediáticos alternativos, populares y comunitarios surgieron bajo el ala del obispo De Nevares y fueron herramientas fundamentales para la defensa de los derechos humanos a nivel provincial y nacional, ya que, por ejemplo, el Obispo fue miembro de la Comisión Nacional sobre la Desaparición de Personas (CONADEP) durante los años 1983 y 1984. Además, junto con las Madres de Plaza de Mayo, filial Neuquén, De Nevares fundó la Asamblea Permanente por los Derechos Humanos en 1975.

«Don Jaime», como lo llamaban popularmente los neuquinos, había sido claramente influenciado por la concepción que sobre los medios de comunicación y sobre el empoderamiento de las organizaciones sociales populares difundieron las Conferencias Episcopales de Medellín (1968) y de Puebla (1979).

A partir de los editoriales principales y de los subeditoriales «Habla Jaime» publicados en la revista Comunidad, se analiza el discurso del obispo De Nevares en relación con la defensa de los derechos humanos y su repercusión en el accionar político de la provincia más allá de su rol como Obispo de la Iglesia católica. Para ello, contamos con un nutrido corpus documental édito e inédito sobre el obispo y su diócesis, que permite realizar el análisis hermenéutico de esta fuente central. 


\section{Jaime de Nevares: un obispo en defensa de los derechos humanos}

Jaime Francisco de Nevares (Buenos Aires, 1915; Neuquén, 1995), obispo de Neuquén entre 1961 y 1991, se transformó en una figura pública por su sensibilidad social y por su liderazgo en la toma de algunas decisiones políticas. «Don Jaime», como lo llamaban en Neuquén, interactuó con un contexto histórico que lo interpelaba y al que supo dar respuestas contrahegemónicas que «insinúan en la mentalidad colectiva modos de ver, que antes o después, habrían tenido incidencia sobre el comportamiento individual y colectivo» (Stella, 1988, p. 8).

Uno de los hitos que lo convirtió en «Don Jaime» fue su lucha por los derechos humanos. A nivel nacional, su episcopado transitó décadas

[de] politización y radicalización de buena parte de los sectores medios y populares de la Argentina en un contexto político e institucional caracterizado por la intolerancia política y la inestabilidad, generando alternancias cívico militares. Este periodo también comprende en su interior la posterior regresión y derrota de esas fuerzas populares a manos del modelo neoliberal y las políticas de destrucción del estado asistencial o benefactor como parte de esta política de represión y desató la más oscura de las persecuciones políticas y sociales dando por resultado una práctica sistemática y desembozada del secuestro, el exilio y el asesinato (Bohoslavsky, Debattista \& Masés, 2012, p. 209).

En los inicios de su vida episcopal fueron trascendentes las enseñanzas del Concilio Vaticano II (1959) y de las Conferencias de Medellín (1968) y de Puebla (1979). . Durante la última Dictadura cívico eclesial militar, De Nevares se posicionó dentro y fuera de la Iglesia. «Como ocurre en situaciones similares, la reacción de los distintos sectores sociales fue dispar, oscilando entre la desinformación, la indiferencia, el temor, el ocultamiento, la justificación, la complicidad, la oposición, la denuncia y la resistencia activa» (Mignone, 1996, p. 136). ${ }^{2}$ Sin dudas, la sociedad le reclamaba a la Iglesia un gesto y una palabra firme en sus pedidos de justicia.

En ese momento, el episcopado oscilaba desde quienes brindaban su apoyo explícito como los monseñores Adolfo Tortolo y Victorio Manuel Bonamín, que exaltaban doctrinariamente la acción del ejército como un «proceso de purificación», hasta quienes 
cayeron asesinados por oponerse al régimen como el obispo de la Rioja, monseñor Enrique Angelelli, el obispo de San Nicolás, monseñor Carlos Ponce de León, los curas palotinos y las monjas francesas, entre otros.

Dentro de ese marco, mientras la Conferencia Episcopal adoptaba una posición de extrema prudencia, limitándose a contactos privados y secretos, y a la emisión de documentos genéricos que reiteraban conceptos doctrinarios sin señalar responsables, unos pocos obispos se lanzaron a una actividad de denuncia pública, a la atención, la protección y la defensa de las víctimas y sus familiares, y a la participación en organismos en defensa de los derechos humanos (Mignone, 1996, p. 136).

La fundación, en 1975, de la Asamblea Permanente por los Derechos Humanos (APDH), que acompañó a las Madres de Plaza de Mayo en sus marchas y en la búsqueda de sus hijos/as, fue el hecho determinante y sin vuelta atrás del episcopado neuquino. A través de la «Marcha por la Vida», De Nevares encontró el espacio para legitimar su propia representatividad y para «la construcción del "nosotros" para el Movimiento de Derechos Humanos $^{3}$ y algunos otros colectivos que se identifican con principios comunes, como sujeto mítico» (Nicoletti \& Mombello, 2005, p. 77).

A partir de allí, como señala Elizabeth Jelin (2017), surgieron los organismos «afectados» (Madres de Plaza de Mayo, Abuelas, familiares de desaparecidos por cuestiones políticas) y los organismos «no afectados» (integrados por personas cercanas a las víctimas, políticos, religiosos de determinadas iglesias, profesionales e intelectuales independientes). Desde este último grupo fue que De Nevares fundó la APDH filial Neuquén.

El círculo de su trabajo por los derechos humanos se cerró con su participación en la CONADEP y con las «Marchas por la Vida», que se realizan todos los 24 de Marzo en la capital provincial encabezadas por la filial Neuquén de las Madres de Plaza de Mayo, quienes luego del fallecimiento de De Nevares portan una pancarta con su retrato para recordar el lugar que el Obispo ocupó junto a ellas hasta 1991. Detrás la APDH, que a partir de los noventa sumó la Corriente de Militantes por los Derechos Humanos (CMDH), luego HIJOS, los gremios (encabezados, generalmente, por ATEN y ATE, CTA y SEJUN), las escuelas, la Universidad Nacional del Comahue y los partidos políticos. 
El Concilio Vaticano II y las Conferencias de Medellín

y de Puebla como claves inspiradoras

Para adentrarnos en el proyecto comunicacional del obispado neuquino, resulta relevante destacar tres factores clave para su desarrollo: el Concilio Vaticano II (1959), la II Conferencia General del Episcopado Latinoamericano (1968), desarrollada en Medellín, que fue parte fundamental de las tendencias renovadoras y progresistas de la cúpula eclesiástica latinoamericana, y la Conferencia de Puebla (1979), que retoma a los medios de comunicación como «vehículos de nuevas pautas y modelos culturales» (p. 73).

En 1959, el obispo De Nevares formó parte de las sesiones del Concilio Vaticano II, que impulsó el Papa Juan XXIII y que continuó el Papa Pablo VI. ${ }^{4}$ El Concilio propuso una renovación de la Iglesia y un acercamiento a las necesidades que demandaba el contexto social, político y económico del momento. En la diócesis de Neuquén, estas ideas impulsaron, entre otras cosas, a los medios de comunicación como un modo de contacto y de desarrollo social destinado especialmente a la juventud en pos de alcanzar una sociedad igualitaria (SERPAC, 2016). De Nevares vio aquí una herramienta fundamental para llegar a la comunidad, más aún en una sociedad de gran movilidad social como la neuquina.

El segundo elemento central fue la II Conferencia General del Episcopado Latinoamericano, realizada en Medellín, Colombia, en 1968, luego de que De Nevares retornara de su primer recorrido por el norte neuquino, con «el corazón conmovido y el alma llena de indignación ante tanta injusticia, maldad, explotación del humilde e insensibilidad»(De Nevares, 1990, p. 13). En relación con los medios de comunicación social y sus usos, en la Conferencia se concluyó que estos eran esenciales para activar a la sociedad hacia un bien común de transformación social que permitiera despegarse de las estructuras verticales y conservadoras, y establecer organizaciones horizontales, donde la misma sociedad pudiera expresarse y dar a conocer información que sensibilizara el cambio social (Conferencia de Medellín, 1968). En el documento final, se hacía hincapié en la formación y en la capacitación comunicacional de los religiosos y los curas para poder brindar herramientas a la sociedad, al tiempo que se reconocía:

El derecho de la Iglesia a poseer medios propios, que en algunos casos son para ella necesarios, es requisito indispensable para justificar esta posición, no sólo contar con una organización que garantice su eficacia profesional, económica y administrativa, sino también que preste un servicio real a la comunidad (Conferencia de Medellín, 1968, p. 57). 
Como tercer elemento clave para la conformación del proyecto comunicacional del obispado neuquino, destaca la III Conferencia General del Episcopado Latinoamericano, celebrada en Puebla, México, en 1979. En el documento final se remarcaron, entre otras cosas, los avances alcanzados en los últimos diez años (desde la última conferencia), así como la proliferación de organizaciones sociales en y para sectores populares. En relación con los medios de comunicación social, los participantes marcaron la necesidad de acudir a las nuevas tecnologías y de no quedarse «atrás», recalcaron la necesidad de que la comunicación social fuera parte de la formación sacerdotal y resaltaron que dichos medios habían funcionado como una herramienta fundamental para la integración social y como vehículos para nuevas pautas culturales. «Reconocemos que los Medios de Comunicación Social son factores de comunión y contribuyen a la integración latinoamericana así como a la expansión y la democratización de la cultura» (Conferencia de Puebla, 1979, punto 1068).

Ante la influencia de estos tres acontecimientos significativos, a mediados de la década del setenta, el obispo neuquino decidió convocar a su par Miguel Hesayne, ${ }^{5}$ al sacerdote Rubén Capitanio y a laicos como Magín Páez, entre otros, para generar proyectos comunicacionales con las comunidades de Neuquén y del Alto Valle de Río Negro. A Páez, específicamente, le encargó conformar la Pastoral para la Comunicación que fue la primera Pastoral de comunicaciones (1979) desde un obispado en el marco de la última Dictadura cívico eclesial militar. Esta Pastoral tuvo como herramientas fundamentales la revista Comunidad, que surgió en 1980, y la Radio Comunidad «Enrique Angelelli», que contó con una inicial sala de grabación en 1987.

Alternativos, populares y comunitarios, los medios surgidos bajo el ala de Jaime de Nevares fueron herramientas fundamentales para transmitir todo lo que los medios hegemónicos no «podían» o no querían comunicar. Como afirma el mismo Páez, respecto del encuentro de Medellín: «Apenas salió ese capítulo, todos empezamos a trabajarlo, y a todos, a mí fundamentalmente, me marcó el camino» (comunicación personal, o7/o7/2016).

De este modo, en 1979, desde el obispado de Neuquén se crea el Servicio para la Comunicación y Capacitación (SERPAC), ${ }^{6}$ que conglomeró una idea en tanto integración social y rol de los medios de comunicación a partir de que el obispo De Nevares reuniera a sacerdotes y a religiosos que caminaron juntos la línea «progresista» de la Iglesia, que se enriqueció con los encuentros antes relatados y que marcó el inicio de una nueva etapa en comunicación popular y alternativa norpatagónica. 
En los tres acontecimientos mencionados, observamos la necesidad de la comunidad neuquina de involucrarse y de comprometerse con la sociedad que los rodeaba y de poder disponer de los medios de comunicación social como herramientas para llevar a cabo este acercamiento y este cambio. Y el motor para iniciar nuevos proyectos comunicacionales fue la diócesis de Neuquén.

\section{La revista Comunidady la actividad editorial}

Una de las primeras actividades editoriales fue la revista Comunidad, lanzada en 1980.

En un contexto donde «la junta militar que tomó el poder en 1976 utilizó de manera sistemática los medios de comunicación como espacio de construcción de un discurso oficial que eliminara otras voces» (Varela, 2001, p. 1), se hizo cada vez más difícil pensar cualquier alternativa que estuviera por fuera de los parámetros oficiales, lo que generó censuras discursivas, «bajada de línea editorial» y estatización de medios, entre otras cosas. Páez, por ejemplo, cuenta que «de un día para el otro» le negaron el ingreso a Radio $\mathrm{LU}_{5}$, en donde tenía su columna diaria, porque había cosas que «no se podían decir». Esto mismo le sucedió a varios comunicadores de la región que no pudieron continuar con su trabajo «por las medidas expuestas por el gobierno de facto» (comunicación personal, o7/o7/2016).

Este contexto de censura y de exclusión fue lo que determinó que Páez decidiera iniciar nuevos proyectos en el marco del SERPAC. Con el aval y a pedido de Jaime de Nevares, reunió a profesionales y a interesados de la comunidad en ocupar un espacio que sirviera de contención ante la represión y la censura desde la comunicación, y en la navidad de 1980 nació Comunidad. Con el respaldo del obispado neuquino y de los integrantes de la Pastoral de comunicaciones comenzaron a editar los primeros números de la revista, que alcanzó los 2 ooo ejemplares por tirada. Si bien el armado de la publicación se produjo sin un subsidio económico fuerte, esta pudo continuar y hacer frente a procesos de censura y de exclusión. Como menciona Páez, «nadie quería figurar. En los primeros números aparecía solo mi nombre: Editor: Magín Páez» (comunicación personal, 07/07/2016). En tanto, se decidió ubicar las oficinas en el patio del obispado, lugar donde las fuerzas armadas quedarían expuestas si ingresaban. 
La revista Comunidad publicó 56 números que fueron editados entre diciembre de 1980 y septiembre de 1990, sin una periodicidad fija pero con ciertas características comunes que resulta pertinente remarcar, ya que guiarán el eje comunicacional del SERPAC y sus posteriores réplicas comunicacionales. Todos los números (que tenían un promedio de 40 páginas) contaban en la primera página con un índice, luego con un editorial firmado por el presidente del SERPAC, Magín Páez, y, a continuación, con artículos de opinión e informativos. ${ }^{7}$ En el segundo editorial (1981) se retomaba el documento de la Conferencia Episcopal de Puebla (1979) y se afirmaba que cada miembro de la comunidad debía poder expresarse libremente y poseer medios afines a la libre comunicación; en el editorial del número 16 (1984) se afirmaba que la publicación buscaba ser la «voz de los que no la tienen, [el] medio de comunicación de las comunidades (...)».

Los editoriales variaron en su contenido y fueron reflejando el contexto. Varios números se dedicaron a los 25 años de la Diócesis de Neuquén (1986), también se trataron temas como la figura de Jaime de Nevares, la visita al país del Papa Juan Pablo II, los medios de comunicación, la situación económica, la problemática mapuche con el Estado nacional, etc. En algunos editoriales se abordaban aspectos más sensibles a nivel social como la justicia, la desocupación, la democracia, la juventud, la paz y la solidaridad, mientras que en otros se buscaba interpelar a la comunidad con temáticas como las elecciones democráticas, el compromiso social, la participación en el trabajo comunitario o las comunidades eclesiales de base.

En los editoriales no siempre se hizo referencia al contenido de la revista, sino que se desarrollaron aspectos de todo tipo, siempre desde un lenguaje coloquial que buscaba interpelar al lector. Al respecto, podemos destacar el editorial del número $24 \mathrm{y}$ el «subeditorial» denominado «Habla Jaime», con palabras del mismo Obispo sobre diversas temáticas (que ahondaremos en el último apartado, específicamente, respecto a los derechos humanos); o el editorial del número 43 (1987), donde se exponían los inicios de la radio «Enrique Angelelli». En esta edición y en las siguientes, la comunicación ocupa un lugar prepronderante: «La comunicación es una necesidad y no puede esperar. Los grandes medios responden a intereses económicos partidarios pero no están en primer lugar como un servicio de comunicación» $\left(1987, N .^{\circ} 43\right)$.

El contenido de la revista fue virando de acuerdo al contexto nacional y a las problemáticas que se creía pertinente abordar. En los primeros números se encuentran muchas notas referidas al gobierno de facto y contra el ministro de economía, Martínez 
de Hoz, el General Videla o las Fuerzas Armadas en general. Estas notas eran acompañadas por entrevistas al mismo De Nevares o a figuras como Adolfo Pérez Esquivel, que denunciaban abiertamente el accionar represivo del gobierno militar. Las «comunidades eclesiales de base» tuvieron una posición preponderante en seis números de la revista. Lo destacamos ya que de dicho movimiento se rescataba la idea de participación ciudadana en el conjunto de los sectores populares.

Si bien la revista no llegó a escribirse más allá del periodo en el que Jaime de Nevares fue obispo de Neuquén, logró abrir una brecha comunicacional muy rica, mediante la cual fue posible canalizar información que los medios hegemónicos no publicaban. En el periodo que estuvo vigente, el equipo que la editaba logró producir afiches, folletería, historietas, calcomanías, adhesivos y cartillas con diversas temáticas; en muchos casos, como soporte para talleres de capacitación (SERPAC, 2016).

Entre otras actividades relacionadas con la producción editorial, se pueden mencionar: el libro documental La verdad nos hará libres, editado en 1990por Nueva Tierra, que reúne documentos de archivo del obispado, publicaciones y fotos de la revista; la primera edición de la agenda latinoamericana, coeditada en 1992 junto con la revista nicaragüense Nicarao, en «celebración por los 500 años de la conquista de América por los europeos»; y el proyecto «Memoria de la tierra», editado en 1996 con apoyo del gobierno nacional, y destinado a las comunidades mapuche e indígenas de la provincia (SERPAC, 2016, p. 4).

Más allá del significado material, cabe destacar la importancia simbólica que alcanzó la revista durante los quince años en los que fue editada. Esto se debe a que la publicación permitió, por un lado, efectivizar un proyecto comunicacional en un periodo dictatorial de censura y de exclusión; por otro, dar a conocer a la comunidad neuquina acontecimientos e informaciones que se mantenían ocultos, aspecto que contribuyó al acercamiento a otros proyectos, como la radio comunidad «Enrique Angelelli».

\section{Radio Comunidad «Enrique Angelelli»}

En 1983, año en el que surgen las primeras radios comunitarias en el país (Kejval, 2009), el SERPAC comenzó a esbozar una idea de proyecto radial. Al no tener los equipos ni los fondos necesarios, el grupo de profesionales que trabajaba en la revista decidió comenzar a grabar en casette sus trabajos como «micros» para enviarlos a la única radio de la ciudad y al interior, y así comenzaron a comunicar en otros formatos. Siguiendo con 
la dinámica anterior, montaron la sala de grabación en el patio del obispado, ya que era el lugar en el que podían trabajar con mayor libertad, sin molestias externas y bajo el amparo institucional del obispado.

La apertura democrática permitió la aparición de numerosos medios que por censura y por represión se encontraban en la clandestinidad. Pero fue a partir de 1987 que el fenómeno de la radiofonía popular se extendió masivamente bajo un imaginario de esperanza, en el que herramientas como la radio se establecieron como elementos clave de transformación social ante la crisis de representatividad vivida durante el periodo anterior. Neuquén no fue la excepción, ya que circunstancias que atentaban contra los derechos democráticos -como la sublevación de Aldo Rico durante Semana Santa de 1987- despertaron la alarma de varios integrantes de la Pastoral de comunicaciones que decidieron crear oficialmente la radio para defender el sistema constitucional. Como forma de «acercarse a una concepción donde la comunicación es concebida como relación, diálogo y articulación capaz de producir nuevos sentidos» (Kejval, 2009, p. 68), y en cuyo marco se pudiera convocar y movilizar a la comunidad en defensa de la democracia y los derechos humanos, como sugería la Conferencia de Puebla (1979).

Fue así como el SERPAC le pidió prestado al secretario del Obispo, Juan San Sebastián, el pequeño transmisor de frecuencia modulada que se utilizaba para la procesión anual y nació FM 105.7 Radio Comunidad «Enrique Angelelli». ${ }^{8}$ La razón por la que la radio nacía oficialmente estaba clara y no tardó demasiado en establecerse la línea marcada por Jaime de Nevares. El nombre mismo, avalado por el Obispo, mostró la importancia de exponer a la comunidad la defensa de los derechos humanos.

La marcada línea popular y comunitaria de la radio, como su gran repercusión y la rapidez con la que se incorporó a los hogares, llamó la atención de organismos conservadores. Páez refiere que recibieron llamadas anónimas que les decían cosas como «déjense de joder con ese Angelelli o los vamos a reventar», pero en lugar de amedrentarse, los integrantes de la radio grabaron estos mensajes y los expusieron al aire (comunicación personal, 07/07/2016). De la misma manera que hizo De Nevares cuando vio personas que lo iban a «vigilar» a las misas o a las procesiones: en vez de resguardarse los expuso en público, dejando clara su postura y dando a conocer a la comunidad las personas que avasallaban sus derechos humanos. La radio, sus fundadores, sus usuarios y sus oyentes pasaron a ser fieles defensores de los derechos humanos y comunicacionales mediante un soporte mediático que se instituía en su resguardo. 
Si bien desde el SERPAC se generaron muchos proyectos, la radio ocupó el centro de la escena por una cuestión de alcance, de rapidez y por la relación que se generaba con otros medios y organismos, debido a la explosión de las radios comunitarias en el país y por la libertad en sus expresiones. Desde la radio se entablaron contactos con instituciones del exterior como el acuerdo con la fundación «Adveniat» (Alemania), que en 1989 facilitó un móvil; el convenio con radio «Nederland» (Holanda), que en 1997 proporcionó un receptor satelital; o la gestación de la Asociación Norpatagónica de Radios Populares, en 1990 (SERPAC, 2016). Además de la adhesión a la Asociación Latinoamericana de Educación Radiofónica (ALER), en 1997, es destacable el rol de la radio como socio fundador del Foro Argentino de Radios Comunitarias (FARCO), en el que actualmente se enmarca la mayoría de las radios comunitarias del país y desde donde surgieron comisiones de trabajo para la discusión sobre la Ley 26.522 de Servicios de Comunicación Audiovisual, sancionada en 2009.

A modo de síntesis, podemos decir que la radio «Enrique Angelelli» nació en un contexto social adverso, lo que la llevó a ser clave en la defensa de la libertad de expresión y de los derechos humanos. El proyecto radial, pionero en la comunicación popular patagónica y nacional, no solo fue un éxito local, al que se integraron varios agentes de la comunidad, sino un ejemplo para la creación de otras radios alternativas, populares y comunitarias en el resto del país. La radio comunitaria, como otras plataformas, adoptó un posicionamiento político orientado a darle voz a los sectores marginados y a constituirse en una alternativa comunicacional (Simpson Grimberg, 1986) que empoderara el entorno al cual se remitía. En materia de defensa de derechos humanos, la radio continúa siendo medio clave para la capital neuquina y uno de los portavoces de las Madres de Plaza de Mayo, con un programa radial que se emite hasta la actualidad.

\section{«Habla Jaime» sobre los derechos humanos}

El análisis de los editoriales sobre derechos humanos, permite

indagar cómo los actores aprovechan (o no) las oportunidades políticas que encuentran en su confrontación con las instituciones y con otros actores. Lo importante y significativo de Derechos Humanos Argentinos fue que, en un momento crucial de la historia, en vez de aprovechar o desechar, el movimiento fue el actor más significativo en cuanto a generar o definir nuevas oportunidades políticas (Jelin, 2017, p. 87). 
Como desarrollaremos a continuación, la línea editorial del SERPAC se encontraba ligada al accionar evangélico que practicó Jaime de Nevares a lo largo de su trayectoria como obispo en la provincia de Neuquén.

Los editoriales de la revista Comunidad reflejaron el posicionamiento político y social del obispado y del equipo de comunicación SERPAC. Por ejemplo, ya en el editorial de su número lanzamiento se expone: «Somos conscientes que muchas veces la realidad nos quema y siempre la palabra de Dios es exigencia de cambio y conversión, y siendo fieles a nuestra misión como Cristo lo fue, "Comunidad" será también como El, piedra de tropiezo para muchos» $\left(1980\right.$, N. $^{\circ}$ o). Según palabras del director, este editorial y todos los restantes, si bien eran consensuados por el equipo editorial, llevaban su firma.

Los primeros doce ejemplares se publicaron durante la última Dictadura cívico eclesial militar hasta el número 13, que se publicó en democracia. Resaltamos esto ya que desde el obispado y a través de su Pastoral de comunicaciones se explicitó el posicionamiento en defensa de los derechos humanos en línea con los documentos del episcopado.

En el número siguiente (abril de 1981, N. ${ }^{\circ}$ ), el editorial menciona el contenido de la revista sobre la «problemática indígena», que también tuvo su pastoral aborigen y atención especial y personal de Jaime de Nevares. Asimismo, destaca la nota sobre el asesinato del obispo Oscar Romero, pastor de la iglesia de El Salvador, asesinado en 1980 por la Dictadura. En el número posterior (junio de 1981, N. ${ }^{2}$ ), se hace referencia a una entrevista realizada a Adolfo Pérez Esquivel, en la que se remarca la necesidad de «luchar sin descanso por la Paz, la Verdad y la Justicia», postura que se explicita aún más en el tercer número (agosto de 1981). En el editorial de esta edición se señala la justicia que merecen los trabajadores en contexto de protesta, y desde el titular de una nota interior de dos páginas se enfatiza: «El Obispo De Nevares denunció "detenciones arbitrarias" exponiendo una carta abierta al gobernador del momento manifestándose en contra del accionar de las fuerzas armadas en la capital neuquina». ${ }^{9}$

En marzo de 1982, el editorial del número 6 exponía:

¿Vamos a celebrar la depresión económica en la que ha caído el país? ¿A festejar el millón de desocupados? ¿Tal vez la victoria? Sobre los más de 6.000 desaparecidos que les queman ya las manos, que tendrán que cargar todas sus vidas en sus conciencias, y esto sin hablar de otros delitos contra los «Derechos Humanos "Menores"». Tal vez la «derrota» sea otra vez de la esperanza de un pueblo nuevamente defraudado, y esta vez con heridas muy profundas. 
Es la primera vez que en un editorial de la revista se menciona la palabra «desaparecido» y se la relaciona discursivamente con los «Derechos Humanos», a los que se suma el derecho al trabajo. Tal como lo había explicitado De Nevares durante el encuentro «Semana por la vida» realizado en Chile, ${ }^{10}$ en acompañamiento a los obispos de este país:

[...] quiero aclarar que cuando hablamos de Derechos Humanos en este contexto nos estamos refiriendo a estos hechos fundamentales de la vida, de la integridad física, de la libertad, de la justicia, de la defensa. Hay otros muchísimos derechos, y no es que se me olviden, ni que se desprecien; pero así fue en la Asamblea Permanente de Derechos Humanos: tuvimos que ceñirnos -era tal el trabajoa estos. Por lo demás, derecho al trabajo, derecho a la educación, derecho a la capacitación, vivienda, y todo eso, no quedan relegados ni en el pensamiento ni en el deseo de trabajar por ello... El Papa dedicó un capítulo importantísimo a la defensa de los Derechos Humanos y pidió a los embajadores que transmitieran lo que había dicho a sus respectivos gobiernos, al año siguiente, que fue el último de su vida. El dedicó totalmente la alocución a los embajadores y a los Derechos Humanos. ¿Se estaría metiendo en política? Y dice así: «La Iglesia y los creyentes no pueden permanecer insensibles e inertes ante la multiplicación de las denuncias de torturas, de malos tratos, practicados en diversos países, sobre personas arrestadas, interrogadas o puestas bajo vigilancia o en estado de detención» (Archivo Pastoral de Migraciones de Neuquén, 22/8/85).

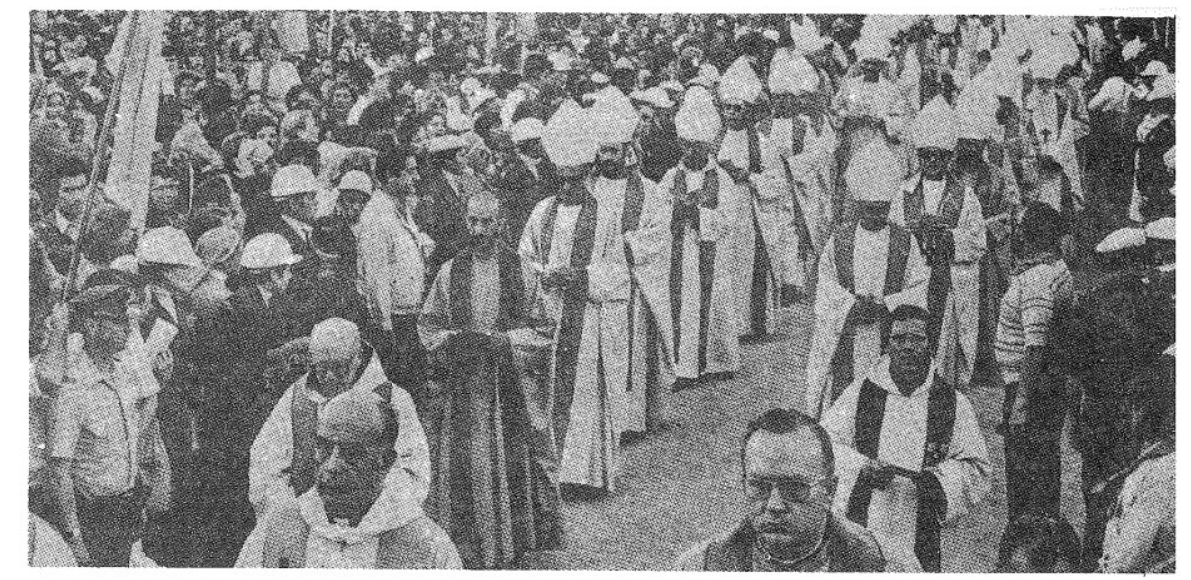

OBISPOS CHILENOS

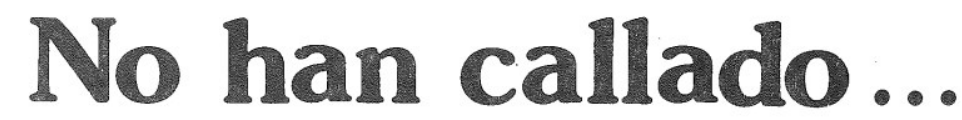

Ante la creciente espiral de violencia y la angustiosa situación

social, económica y politica de Chile la Iglesia en ese país

hermano defiende la dignidad del hombre. 
Como explicaba De Nevares en su conferencia durante «Semana por la Vida», lo acuciante durante las dictaduras eran los derechos relacionados con la integridad física y la libertad de la persona, pero una vez que la democracia resguardaba esos derechos fundamentales, la lucha se ampliaba a todos los aspectos de la vida de las personas en el orden social como el trabajo, la vivienda digna, la educación, la salud, etc. Este señalamiento se repetirá en los sucesivos números, en los que, por ejemplo, figuran notas como «Declaración Universal de los Derechos Humanos» (junio de 1982, N. ${ }^{\circ}$ ), que se publican acompañadas de ilustraciones más que elocuentes que dejan en total evidencia a las Fuerzas Armadas por el avasallamiento de los derechos humanos en democracia. En diciembre de 1982 (N. ${ }^{\circ}$ 9), la revista alude al proceso de concertación llamado por el gobierno de facto y en el editorial se indicaba: «Los obispos nos dicen que sin verdad y justicia no habrá reconciliación auténtica», utilizando el apelativo «verdad y justicia» que luego será bandera en el reclamo por los derechos humanos.

Esto último se reafirmará en el editorial del número 10, publicado en mayo de 1983:

Por eso COMUNIDAD, con nuestro Obispo, sacerdotes y demás voces que se han levantado en estos días, dice: NO a la mentira, a la tortura, al asesinato, prisión injusta, desapariciones y demás secuelas de estos últimos 7 años de represión. Decimos: SI a la vida, a la justicia, a la verdad, paz y amor.

En dicho número, el editorial se refuerza con notas como «Sacerdotes y pastores desaparecidos», «Sobre la declaración de las FF.AA»y «Oración y los derechos humanos», que vuelven a marcar la línea ideológica del obispado neuquino, de Jaime de Nevares y de sus pastorales. A esto se suma, en el número siguiente (julio de 1983), la mención, por primera vez, a las Madres de Plaza de Mayo «y [de] tantos que dieron la vida y luchan». En el número 12, publicado en vísperas de las elecciones, el editorial interroga: «¿Dónde estaban, entonces, cuando nuestros hermanos y hermanas, nuestros hijos y nietos desaparecían?»."

Los editoriales que suceden al periodo dictatorial cubrirán numerosas temáticas, pero el tópico referido a los derechos humanos estará presente hasta el final de la revista (1990). Por ejemplo, en septiembre de $1984\left(\mathrm{~N} .^{\circ}{ }^{15}\right)$, se trata la temática de la CONADEP y, en mayo de 1985 (N. $\left.{ }^{\circ} 18\right)$, el lema del «Nunca más» o el «Punto final», con una nota en la que el propio De Nevares reflexiona sobre el nuevo proceso democrático y los derechos humanos en relación con los/as desaparecidos/as durante la Dictadura cívico eclesial militar. 
En el número 24 (noviembre de 1985) se publica una nota central titulada «Juicio: ¿Fin o Principio?», respecto de la cual el editorial señala: «No necesita presentación. Porque ya COMUNIDAD ha desarrollado el tema y la postura de nuestra Iglesia de Neuquén en casi todos los números y no nos cansaremos de hacerlo».

Sin embargo, lo destacable de este número es que comenzó a publicarse una doble editorial denominada «Habla Jaime», espacio en el que el Obispo abordaba determinadas temáticas. Desde el número 24 y hasta el número 55 (1990), las temáticas de derechos humanos fueron tratadas tanto en los editoriales tradicionales como en este apartado, en el que De Nevares escribía en primera persona.

En relación con los derechos humanos, luego del retorno a la democracia ni los editoriales ni el apartado «Habla Jaime» fueron tan directos o incisivos como en los primeros doce ejemplares. Se abordaron temáticas como las problemáticas laborales (1986, N. $\left.{ }^{\circ} 27\right)$ y el derecho a la participación: «Vemos desatada una reacción en cadena que ve forzado el surgimiento de condiciones de vida más humanas, más justicia, más libertad, más respeto a la dignidad de la persona humana» $\left(1986, \mathrm{~N}^{\circ}{ }^{2} 28\right)$ o mediante referencias a la participación y la alegría, como en el «Habla Jaime» del mismo número. En referencia a los derechos humanos, los editoriales remiten a esto desde tópicos como la «verdad» $\left(1986, \mathrm{~N}^{\circ}{ }^{\circ}\right.$ 30) o la «justicia» $\left(1986, \mathrm{~N}^{\circ} 31 ; 1987, \mathrm{~N}^{\circ}{ }^{\circ}\right.$ 0): « ¿ No sería consolador, reconfortante, ejemplificador que se conociera más y mejor todo lo bueno que acontece en este pobre mundo y se amplificara menos lo negativo, o lo simplemente anodino y superficial?» («Habla Jaime», julio de 1986, N. $\left.^{\circ} 31\right)$.

En la Argentina están sucediendo cosas, hechos, los cuales según como se resuelven, influirán en nuestra historia para bien o para mal. Es claro que me estoy refiriendo, aunque no exclusivamente, a la lucha por la democracia, por la plenitud del poder constitucional, por la vigencia total del Derecho y de la Justicia, seriamente atacadas por determinados sectores de la sociedad, ataques de los cuales los levantamientos de Semana Santa no son más que «la punta del iceberg», las llagas que manifiestan una infección generalizada («Habla Jaime», abril de 1987, N. ${ }^{\circ}$ o).

Se justifica, en el último caso, que la «obediencia debida», por ejemplo, era un escenario claro donde la justicia verdadera se constituía en símbolo de un avance en materia de derechos humanos. Otras reflexiones refieren a tópicos como el desarrollo integral de los jóvenes, los medios de comunicación y la necesidad de construir un escenario 
de memoria: «iNunca más! Lo sensato sería que así fuera; pero no: la locura anda suelta» («Habla Jaime», octubre de 1986, $\mathrm{N}^{\circ}{ }^{34}$ ), «por ello resulta fundamental construir desde los medios de comunicación un espacio de memoria».

La prohibición de olvidar ha sido más constante a lo largo del tiempo y conlleva un operativo de lucha social y simbólica permanente de considerable magnitud. En la visión de los protagonistas del movimiento, la idea guía de esta lucha es que sólo a través del recuerdo permanente de lo ocurrido se puede construir una barrera contra la repetición de atrocidades similares. Como si del recuerdo constante del terror experimentado durante la dictadura pudiera derivar un futuro «Nunca Más» (Jelin, 2017, p. 90).

Los editoriales de la época democrática no abandonaron su foco en los derechos humanos sino que los ampliaron, mediante la exposición de problemáticas contextuales a nivel nacional: «Todo lo que venimos viviendo en el país (sobre todo en los últimos meses) es un muestrario de cómo no debe funcionar una sociedad: uno de los primeros Derechos Humanos reconocidos, el de trabajar, ya lo han perdido ciento de miles de argentinos [...]» (julio de 1989, N. ${ }^{\circ}$ 1); aspecto que De Nevares reforzó en el apartado «Habla Jaime», mediante una carta de los obispos de la región en oposición a las medidas económicas del gobierno nacional en perjuicio de los sectores populares y medios.

\section{Reflexiones finales}

A lo largo del trabajo, expusimos la posición ideológica discursiva y el accionar pastoral del obispo Jaime De Nevares en defensa de los derechos humanos en plena Dictadura cívico eclesial militar en la diócesis de Neuquén. A partir de los editoriales tradicionales y de los subeditoriales «Habla Jaime» de la revista Comunidad fue posible analizar su protagonismo en la defensa de los derechos humanos reflejada en una acción pastoral que trascendió el ámbito de su diócesis y de la misma Iglesia Católica y que lo llevó a transformarse en una figura pública.

Nos enfocamos en la confección de una pastoral de la comunicación en función de la acuciante problemática de la defensa de los derechos humanos desde una institución que por acción u omisión tuvo participación, al igual que parte de la sociedad civil, en la «desaparición de personas». Dentro de un minoritario grupo de obispos de la Asamblea 
Permanente del Episcopado Argentino, la figura de Jaime de Nevares se destacó en defensa de los derechos humanos y en oposición a la Dictadura cívico eclesial militar y a los obispos que la justificaban.

En su diócesis, el Obispo desarrolló espacios comunicacionales de expresión y de denuncia en épocas donde dicha acción derivaba en desapariciones, en torturas y en muertes. La utilización de los diversos soportes mediáticos le proporcionó a De Nevares y, posteriormente, a Miguel Hesayne, un posicionamiento desde la institución eclesiástica en relación con los derechos humanos y constituyó la posibilidad de que la misma comunidad canalizara opiniones, reflexiones, demandas, contenido o información libremente, ejerciendo el derecho a la comunicación y la expresión.

Desde la apertura del espacio «Habla Jaime» la voz del obispo De Nevares fue directa y firme. El discurso en primera persona y dirigido explícitamente a la comunidad fortaleció entre el obispo y su entorno un vínculo que será constantemente reconocido. En el último número de la revista Comunidad (1990), sin saber que no habría más ediciones, se dedicaba el espacio editorial al mismo De Nevares:

Jaime que nos ha ido mostrando un camino, una forma de ser y vivir la fe y el compromiso con nuestro pueblo que sufre y lucha. Pueblo que muchas veces también se encuentra confundido e indeciso; que también arrastra su pecado de comodidad, «no te metas», e indiferencia y dolor de los que más padecen el castigo (septiembre de $1990, \mathrm{~N} .^{\circ} 55$ ).

Jaime de Nevares en discurso y en acción dejó una huella profunda en la participación política y en la defensa de los derechos humanos en Neuquén, que fue más allá de los confines de la diócesis y de los límites de la Iglesia católica. Su accionar fue clave en la configuración de una línea de participación activa en materia de defensa de los derechos humanos y en la construcción de la memoria que mantuvo vivos esos derechos y que consolidó nuevos y distintos espacios de trabajo. 


\section{Referencias}

Archivo de la Pastoral de Migraciones de Neuquén (22 de agosto de 1985).

Documento «Semana por la Vida». Conferencia «Nunca Más» por Monseñor Jaime de Nevares.

Bohoslavsky, E., Debatista, S. y Masés, E. (2012). Cultura y sociedad en los tiempos de Monseñor de Nevares. En J. Muñoz Villagrán (Coord.), Pedagogía política de Don Jaime de Nevares. Neuquén, Argentina: EDUCO.

De Nevares, J. (1990). La verdad nos hará libres. Ciudad Autónoma de Buenos Aires, Argentina: Centro Nueva Tierra.

Documentos del Episcopado Argentino (1965-81) (1982). Colección completa del magisterio postconciliar de la Conferencia episcopal argentina.

Ciudad Autónoma de Buenos Aires, Argentina: Claretiana.

II Conferencia General del Episcopado Latinoamericano (Medellín, 1968).

Recuperado de www.diocese-

braga.pt/catequese/sim/biblioteca/publicacoes_online/91/medellin.pdf

III Conferencia General del Episcopado Latinoamericano (Puebla, 1979).

Recuperado de https://www.celam.org/documentos/Documento_Conclusivo_Puebla.pdf

Jelin, E. (2017). La lucha por el pasado. Cómo construimos la memoria social.

Ciudad Autónoma de Buenos Aires, Argentina: Siglo XXI.

Mignone, E. (1996). Dictadura e Iglesia en Quilmes. Contexto para una investigación. Revista de Ciencias Sociales (s/d).

Nicoletti, M. A. y Mombello, L. (2005). La figura del primer Obispo de Neuquén y la construcción de la identidad colectiva local. Revista en Ciencias Sociales y Religión, (7), 49-73.

Kejval, L. (2009). Truchas. Los proyectos político-culturales de las radios comunitarias, alternativas y populares. Ciudad Autónoma de Buenos Aires, Argentina: Prometeo.

Revista de Pie (septiembre de 1986). No han callado..., número 12, p. 19. 
Servicio para la Comunicación y Capacitación (SERPAC). (2016). Documento «Origen e Historia». 38 Aniversario de la Fundación SERPAC 1979-2016. Neuquén, Argentina: SERPAC.

Simpson Grimberg, M. (1986). Comunicación alternativa para el cambio social. Ciudad de México, México: Premia.

Stella, P. (1988). Don Bosco. Nella storia della religiosità cattolica. Vol. III:

La canonizzazione (1888-1934). Roma, Italia: Librería Ateneo Salesiana.

Varela, M. (2001). Los medios de comunicación durante la dictadura:

entre banalidad y censura. Recuperado de

https://www.academia.edu/1072677/Los_medios_de_comunicaci\%C3\%B3n_durante_la_ dictadura_entre_la_banalidad_y_la_censura

\section{Entrevistas}

Don Jaime de Nevares, entrevista realizada en Neuquén el 4 de mayo de 1993.

Magín Páez, entrevista realizada en Neuquén el 12 de julio de 2016.

Fuentes analizadas

«Evangelizar es comunicar, número lanzamiento» (diciembre de 1980), número o. Editorial.

«La Iglesia de Neuquén al servicio de todos» (abril de 1981), número 1. Editorial.

«Editorial» (junio de 1981), número 2. Editorial.

«El obispo en diálogo con Neuquén» (agosto de 1981), número 3. Editorial.

«iÉl vive!» (marzo de 1982), número 6. Editorial.

«Declaración Universal de los Derechos Humanos» (junio de 1982), número 7.

«iEl señor viene!» (diciembre de 1982), número 9. Editorial.

«Editorial» (mayo de 1983), número 10. Editorial. 
«Sacerdotes y pastores desaparecidos», (mayo de 1983), número 10.

«Sobre la declaración de las FF.AA.», (mayo de 1983), número 10.

«Oración y los derechos humanos», (mayo de 1983), número 10.

«Editorial» (julio de 1983), número 11. Editorial.

«Homenaje a Monseñor Angelelli» (noviembre de 1983), número 12.

«Editorial» (septiembre de 1984), número 15. Editorial.

«Editorial» (noviembre de 1984), número 16. Editorial.

«Neuquén habló» (mayo de 1985), número 18. Editorial.

«Juicio: ¿Fin o Principio?» (noviembre de 1985), número 24.

«Platero...» (noviembre de 1985), número 24. Editorial.

«iCon todo!» (marzo de 1986), número 27. Editorial.

«iMás vida!» (abril de 1986), número 28. Editorial.

«Habla Jaime» (abril de 1986), número 28. Subeditorial.

«Verdad» (junio de 1986), número 3o. Editorial.

«Conciencia» (julio de 1986), número 31. Editorial.

«Habla Jaime» (julio de 1986), número 31. Subeditorial.

«Habla Jaime» (octubre de 1986), número 34. Subeditorial.

«Justicia y Paz» (abril de 1987), número 4o. Editorial.

«Habla Jaime» (abril de 1987), número 40. Subeditorial.

«Otra onda...» (octubre de 1987), número 43. Editorial.

«Luz y sombra» (julio de 1989), número 51. Editorial.

«Habla Jaime» (julio de 1989), número 51. Subeditorial.

«¿Cómo?» (septiembre de 1990), número 55. Editorial. 
1 Entrevista a don Jaime de Nevares, realizada en Neuquén el 4 de mayo de 1993.

2 Con prudencia, se refiere a la Primera carta de la Conferencia episcopal (San Miguel, 15 de mayo de 1976) y la Pro-Memoria. Documento entregado por la comisión ejecutiva de la Conferencia Episcopal Argentina a la Junta Militar, el 26 de noviembre de 1977 (Documentos del Episcopado argentino (1965-81), 1982).

3 «La expresión "Movimiento de Derechos Humanos" fue -y sigue siendo- la manera en que los propios actores primero, y la sociedad política en su conjunto después, denominan el conjunto de organizaciones y activistas que llevan adelante acciones públicas y demandas hacia el Estado por el reconocimiento de las violaciones ocurridas durante la dictadura (1976-1983). Las posturas en relación con la noción universal y amplia de "Derechos Humanos" han variado a lo largo del tiempo» (Jelin, 2017, pp. 88-89).

4 El Papa Juan XXIII falleció durante la realización del Concilio.

5 Miguel Hesayne, obispo de la diócesis de Viedma que abarcaba todo Río Negro (1975-1995).

6 Con Jaime de Nevares a la cabeza, el SERPAC congregó a diversas personalidades que se reunieron para idear estrategias comunicacionales con el objetivo de vincularse con la comunidad. Desde allí se conformaron los proyectos mediáticos que se exponen en este artículo.

7 La firma de Magín Páez en los editoriales tenía una doble razón. La primera, y principal, es que él era y es el presidente del SERPAC, espacio desde donde se publicaba la revista. La segunda es que la revista comenzó a publicarse en un contexto de dictadura militar, donde cualquier espacio o muestra de oposición podía ser castigado fuertemente, y Páez, con el respaldo del obispo De Nevares, asume ese riesgo.

8 En honor al Obispo asesinado por la Dictadura en 1976, acto que De Nevares denunció en reiteradas ocasiones como se registra, por ejemplo, en la homilía N. ${ }^{\circ} 2$ del DVD «Esta es Palabra de Jaime», lanzado a los quince años de su fallecimiento.

9 La temática de la justicia se repetirá a lo largo de otros editoriales, pero con más énfasis en los publicados durante el periodo dictatorial.

10 Conferencia «Nunca Más», pronunciada por Monseñor Jaime de Nevares, el 22 de agosto de 1985, en el Instituto Salesiano de Valdivia, Chile.

11 Las Madres de Plaza de Mayo tendrán mayor espacio en el proyecto de la radio comunitaria «Enrique Angelelli», también perteneciente al SERPAC. 